\title{
Experience of the role of contracts in megaproject execution
}

Paul E. Jobling BSC, MSC, CEng, MICE, MAPM

Specialist Consultant, Kingsfield Consulting International, Surrey, UK (corresponding author: paul.jobling@kingsfieldconsulting.com) (Orcid:0000-0001-8797-5609)
Nigel J. Smith BSc, MSc, PhD, CEng, FICE, FCIHT, FAPM, FHEA Professor of Project and Transport Infrastructure Management, Member of the Institute for Resilient Infrastructure and Head of Project Management Group, School of Civil Engineering, University of Leeds, Leeds, UK (Orcid:0000-0002-9695-6685)

The majority of megaprojects fail to achieve their objectives. Studies suggest that up to two-thirds of them do not meet time, cost or performance targets, a much higher proportion than that for conventional projects. Failures are attributed to various causes: stakeholder biases, lack of investment in front-end planning and optimistic estimates and/or schedules, among other factors. Further, it is evident that owners increasingly require larger, more complex projects within compressed timescales. However, even if experience shows that the objectives are unrealistic, there is almost invariably a contractor that is willing to provide a competitive tender for the work. Despite recent improvements in management capability and enhancements to procurement and contracting practices, risk assessment, project planning and control, there has been little noticeable improvement in the outcomes of most megaprojects. This paper, based on both authors' academic and industrial experiences of megaprojects, focuses on another factor, the contract, and provides an alternative view of the contractual context in which megaprojects are to be delivered and how this affects the current practice of scaling up contracts and procedures in an attempt to offer megaprojects levels of certainty similar to those of traditional projects. Indeed, the existing contracting practice may act to militate against the adoption of more appropriate delivery approaches.

\section{Introduction}

This paper takes a view of megaproject delivery and performance over the years and considers this through the lens of the role of the contract. While supported by research papers, guides and case studies, the paper reflects the combined industrial and academic experience of the authors.

An overview of megaprojects is first presented and then the complex nature of these projects investigated. Attention is then given to the role of contracts in megaprojects and the current best practice. The concept of 'incomplete contracts' is introduced, and a critical discussion of the benefits and constraints of contracts

is presented. The paper finally considers whether the role of contracts is something that should be investigated further in attempting to improve the delivery of megaprojects. This paper reviews the performance of megaprojects, concentrating on the role of contracts based on years of experience of research and consultancy work in this sector.

\section{Background to megaprojects}

There are many definitions of megaprojects, many using slightly different terms, such as 'major projects', 'giant projects', 'jumbo projects' or 'large engineering projects' (Lee et al., 2009; Miller and Lessard, 2001; Mousavi et al., 2011), but this paper uses the term 'megaprojects'. In a recent literature review, Sainati (2017) considered ten defining features for characterising megaprojects: economic size, physical tangible outcome, impact on the context, government involvement and political relevance, organisational complexity and heterogeneity, long-time commitment, vast uncertainty and risk, challenging investment, megaprojects as programmes and poor track record of performance. Sykes (1998) identified eight attributes of megaprojects: large size and multiple owners; public opposition to the expected social, economic, political and environmental impacts; development time; location; potential to destabilise markets; unique risks; financing difficulties; and an unpopular career course for senior managers. Galloway and Reilly (2013) presented eight facts about megaprojects: cost above US\$1 billion; multiple-year execution schedules; multinational involvement of designers, engineers, contractors, equipment suppliers and specialty material vendors; specialty trade workforces numbering in thousands of individuals; consortium financing and/or ownership; technical complexity; political ramifications and risks; and social ramifications and risks.

In this paper, any project demonstrating the majority of the attributes outlined by Sainati (2017), Sykes (1998) and Galloway and Reilly (2013) mentioned earlier is considered to be a megaproject.

The bulk of the recently published research papers regarding improvement of the performance of megaprojects rarely, if ever, mention the role played by the contracts between the major parties involved in the project or the contractual frameworks of the projects. Studies of teams, behaviour and conflict have been undertaken, such as that by Fellows and Liu (2010), but do not consider the contractual and legal contexts for managing the relationship between the owner and contractor. On occasion, papers identify the delivery mechanism or payment mechanism(s), but these are not the same as the contractual terms and conditions or the legal framework within which the project is executed. This is a significant lacuna in the literature on the management of megaprojects. 
The legal and contractual position generally appears to militate against changing long-standing approaches because the highly specified relationships between the parties set out in contracts to execute projects do not allow room for innovation and frequently do not encourage it because there is always the risk that a new approach will not comply with the detailed provisions of the contract. This is compounded because it appears that owners and their legal advisors are increasingly risk averse.

\section{Megaprojects and complexity}

While the recognition of complexity in projects is a relatively recent development, the underlying issues and alternative approaches to managing them or modelling them have been identified in previous decades but not fully considered in the development of new contract forms. For instance, the goals-and-methods matrix developed by Turner and Cochrane (1993), reproduced here as Figure 1, identifies the interaction between definition of goals and the application of methods to achieve them. It is noteworthy that Turner and Cochrane (1993) suggested that engineering and construction projects are type 1 projects with well-defined goals and methods, although in reality there were always engineering and construction projects for which this was not true, particularly megaprojects.

The Cynefin framework was developed by Snowden (2002) and Snowden and Kurtz (2003). The domains were originally called 'simple', 'complicated', 'complex' and 'chaotic' and with a centre called 'disorder'. These evolved to the domains shown in Figure 2. Whatever the names, the intent is clear: the domains on the right are ordered, where cause and effect are known or can be discovered. Those on the left are unordered, and cause and effect can be deduced only with hindsight or not at all, which would apply to megaprojects.

Both the goals-and-methods matrix and the Cynefin framework indicate that conventional tools, methods and approaches will not help in managing complex projects through their life cycle and may in fact impede their management.

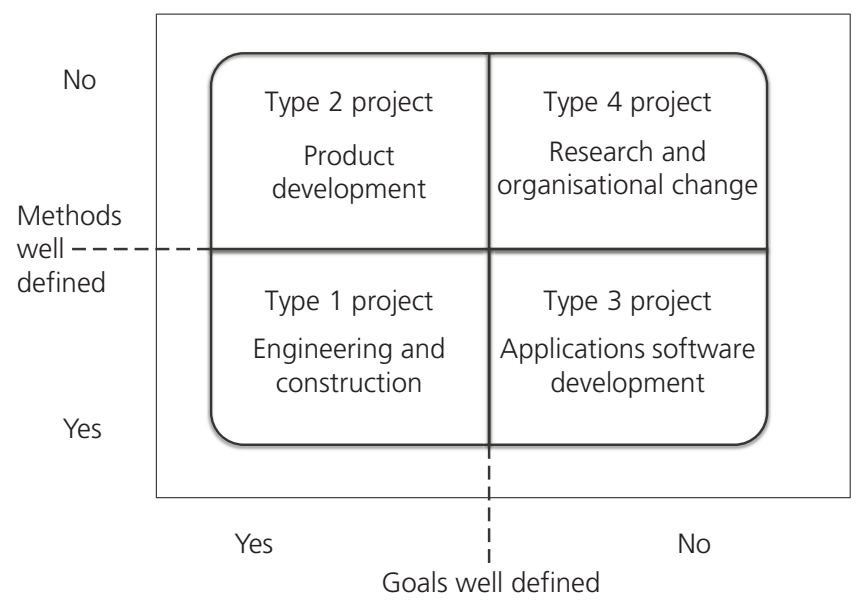

Figure 1. Goals-and-methods matrix

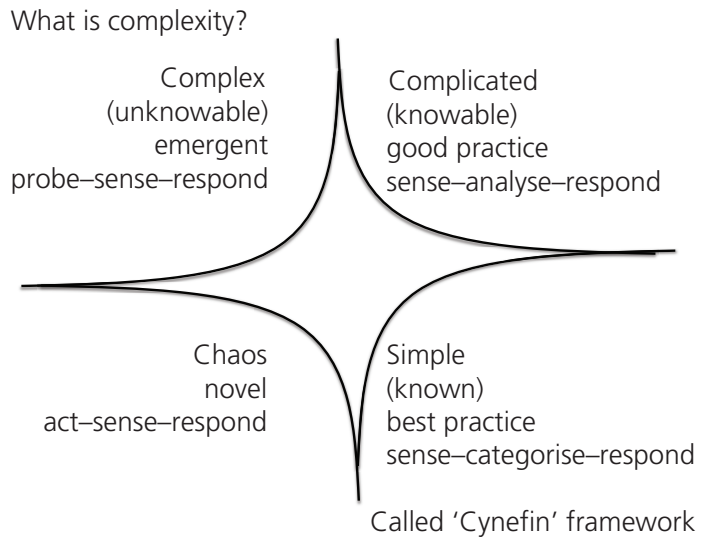

Figure 2. Cynefin domains

A way of visualising complexity in projects was developed by Williams et al. (1995) and modified by Jobling for this paper based on involvement in a recent project (Figure 3). The 'management decision' was to maintain the original completion date because the owner did not accept that it had fundamentally changed the project. The contractor's attempts to maintain the original completion date were unsuccessful and further disrupted its works, compounded all the delays and hence compounded the contractor's costs and losses. The decision is typical of many owners who can ill afford delays to their projects.

Williams (1999) emphasised the need for new methods of analysis and management to deal with increased complexity, noting that traditional models, such as conventional critical-path network schedules, cannot deal with goal or method uncertainty, but apart from a very brief note of the use of contractual mechanisms such as alliancing, there is no further mention of contracts or contractual arrangements.

\section{Performance of megaprojects}

Megaprojects are not new. Sykes (1986) observed that megaprojects, more often than not, are characterised by failure and the majority of the largest and most difficult fail to be launched. Over half of those that are launched subsequently fail. Sykes (1986) noted that the exact point of change from traditional to megaproject cannot be precisely defined; nevertheless the quantitative change has brought about an often unrecognised qualitative change. Hence experience on conventional projects and with conventional contracts has to be applied with caution as it can be misleading.

Megaprojects should be considered as providing additional challenges that cannot be resolved with traditional and operative project management and contractual tools. Flyvbjerg et al. (2003a, 2003b) observed that despite all claims of improvement, forecasting success in megaproject delivery has not improved in 70 years. Dimitriou et al. (2012) emphasised the quality of megaprojects as an open system and agent of change for 


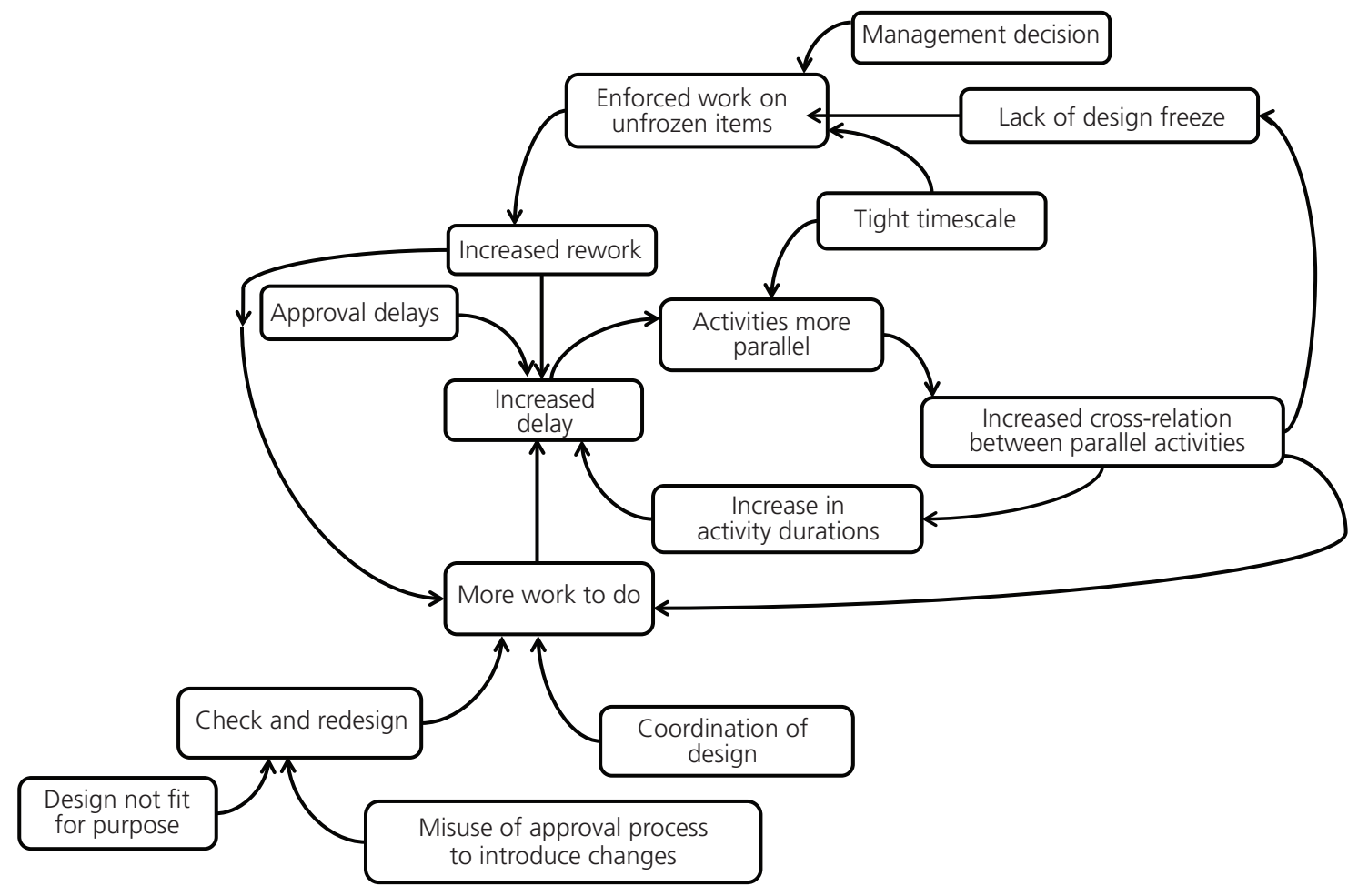

Figure 3. Non-linear complexity (modified from Williams et al. (1995))

implementing context. This view is opposed to the iron triangle (cost, time and quality) that considers projects as closed systems.

The facts are that the performance of megaprojects is very poor. Merrow (2011) showed from a sample of over 300 industrial megaprojects that around two-thirds overran their costs and schedule by over $25 \%$ with execution times over $50 \%$ higher than forecast and suffered severe operational problems into their second year after start-up (for oil and gas megaprojects, this was nearer $75 \%$ of the time). Merrow (2011) also commented on the contracting approach used (engineering, procurement and construction (EPC) lump sum $53 \%$, engineering, procurement and construction management (EPCm) cost reimbursable 25\%, alliances $12 \%$ and mixed $10 \%$ of the sample), noting that after suitable adjustments were made, the lump sum and reimbursable contracts had similar rates of success/ failure but alliances were significantly worse. His study did not identify the precise form(s) of contract used.

It is the case that some projects are unlikely to fulfil their business case, and there should be more recognition that some projects are simply not viable. The term 'optimism bias' became widely recognised in the project world following the publication of Flyvbjerg et al.'s book (Flyvbjerg et al., 2003a). Recognition that estimates were frequently too low predates this publication - for example, Kharbanda and Stallworthy (1983), UMIST PMG (1989) and the unpublished 1986 report by Thompson PA, Perry JG, Nicholson T and Jobling PE, Cost Estimating Study for
Overseas Development Projects - but acceptance that a large contingency sum was required to be added to early estimates took a number of years, and Flyvbjerg et al.'s book (Flyvbjerg et al., 2003a) is credited with being a trigger for that wider recognition.

While the optimism bias approach is a positive step forward in mitigating time and/or cost failures in megaprojects, it is not a panacea. Optimism uplifts require a base from which to adjust the forecasting, as Flyvbjerg et al. (2004) noted. As megaprojects have long durations and high levels of uncertainty, it is difficult to establish the appropriate foundation for the uplift. Equally important is the evidence that around one-third of megaprojects do perform satisfactorily and do not require uplifts, the difficulty being the inability to identify the appropriate third. The potential for a more holistic solution therefore needs to be investigated. A fundamental question is how much the theoretical transfer of risk to the supply chain may influence both the base estimate and the uplift, in other words the viability of the project.

\section{The role of contracts}

Based on the authors' experience, less flexible forms of contract such as the International Federation of Consulting Engineers (Fidic) suite of contracts as set out by Watermeyer (2012), modified versions of standard forms or broadly similar but bespoke contracts have been used and continue to be used for many megaprojects. Recent experience suggests that these are now being tightened up to transfer even more risk to the supply chain, which 
could exacerbate the existing problems. Based on studies of the Fidic 'Silver Book' (Fidic, 2017) model form of contract and amendments thereof, Hosie (2007) suggested that owners wish for greater transfer of risk to contractors than is actually achieved. Hosie (2007) also suggested that tight monitoring and control will provide owners with some assurance that projects will be completed within time, cost and performance targets. As evidenced earlier, this assurance is frequently not achieved for megaprojects.

Recent changes in the Fidic suite of contracts reported by Glover (2017) aim to improve the outcomes of projects, but the changes do not deal with the fundamental problem of increasing complexity. The comments received from contractors' associations indicate their concerns that the proposed changes will simply add to bureaucracy through focusing on disputes rather than seeking to improve the management and delivery processes.

Valentin and Vorster (2012: p. 25) noted the following.

It has been established that it is highly likely that a relationship exists between the probability of contract failure and the type of contract signed by the contracting parties. Although FIDIC and NEC-type model conditions of contract (as well as numerous hybrids) are commonly used, a number of types of contract and sector-specific conditions of contract exist. There is no doubt that conditions of contract documents can be ranked in order of promoting failure. Unfortunately, no reliable data currently exists to do so due to the fact that groups of projects fail rather than individual projects and it is thus not possible to isolate and quantify the relativity of failure in a meaningful way.

Increasingly in the UK and in countries influenced by UK practice, public sector megaprojects such as the 2012 Olympics programme and Crossrail are using the New Engineering Contract (NEC) suite of contracts, with emphasis on the target cost option, a trend started by the Channel Tunnel Rail Link (High Speed 1). Their circumstances as publicly funded major infrastructure projects in one of the world's richest nations are substantially different from the private sector commercial and industrial projects, particularly in less developed and poorer countries. Any conclusions about the contribution to their outcomes made by the form of contract that they used could therefore be misleading.

First, these projects have benefitted from improvements in stakeholder management, improved risk management and other approaches that have emerged in parallel with the adoption of the NEC. For example, Morgan (2011) commented on Crossrail's success and how risk management had contributed to it.

Second, their public funding allows for significant provision of contingency sums that may not be feasible for most projects in the commercial private sector or in less wealthy nations.

In a recent paper, Uff (2017) was highly critical of the claims made for the benefits of using the NEC contracts. Like Valentin and Vorster (2012), Uff (2017) noted the difficulties in carrying out systematic analyses of the outcomes of contracts, including the extreme variability in circumstances in which contracts are drawn up and used, as well as issues of confidentiality and the simple practicality of gaining access to the necessary data.

\section{Best practice: a constraint?}

In recent years, the concept of 'best practice' has become commonplace in industry guidelines, government advice, accreditation schemes and so on. The reasons for this are obvious, but there is a risk that such practices become deeply embedded in the approaches of contractors and the owners and their advisors. From being new approaches at their inception, they move through a cycle developed by Jobling and illustrated in Figure 4.

The cycle starts with their initial identification, followed by usage by a few major users and then more general acceptance as they become more widely used, shared and recommended to the point at which they become recognised as best practice. However, as suggested by the goals-and-methods matrix and the Cynefin framework and as has been observed in practice for megaprojects, there are limits to the applicability of any particular tool, technique or approach. What is perceived as best practice or good industry practice may be applicable only in certain circumstances. Complex megaprojects are now recognised as being applications where traditional approaches, tools and techniques have significant shortcomings and may be at best unsuitable, or at worst counterproductive. Nevertheless, shortcomings notwithstanding, they are often specified in the contract documents used for megaproject execution.

The reasons for the difficulty in scaling from traditional forms of contract can be summarised under three broad headings

risks and uncertainty

- increased complexity leading to increasing unpredictability

aneral uncertainty in the world economy, decreased commodity prices and increased competition

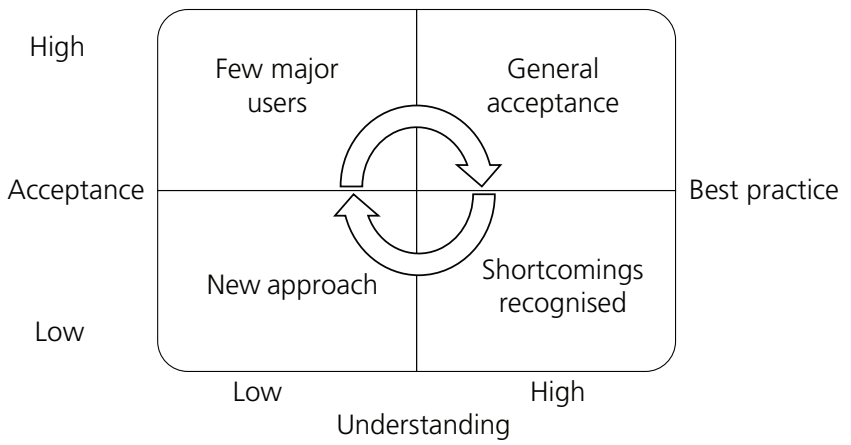

Figure 4. Best practice: the acceptance-against-applicability matrix 
execution

- larger projects mean multiple stakeholders and consortia or joint ventures for both owners and contractors

- increasing multiplicity of potential suppliers in low-cost developing countries

- reduced programme duration and reduced budgets

constraints

- emerging complexity (best practices are no longer applicable)

- resistance to adopting appropriate techniques for legal and cultural reasons.

\section{Incomplete contract: dilemma or constraint?}

Lyons and Mehta (1997) suggested that classical contract theory assumes that for any situation, a complete contract can be drafted. This would include the capability to mitigate adverse effects while specifying everything in detail. Gaski (1984) observed that this apparent level of detail, while effective in some cases, can cause disputes. In practice, the time and cost implications of trying to define completely a long-duration contract mean that most contracts are in fact 'incomplete'. Chen (2000) defined an incomplete contract as an agreement that goes beyond what is verifiable. Incomplete contracts still have duties and controls but recognise that it is just not possible to anticipate every future incident and contingency.

Emphasis is often placed on 'getting the contract right' to include everything. To try to satisfy this need, the production of formal contracts containing highly regulated provisions for the conduct and behaviour of the parties is frequently developed at significant expense, but such contracts will still be incomplete, and possibly counterproductive, as suggested by Zheng et al. (2008).

Following from the discussion of complexity, it would appear inevitable that no complete contract can be drafted for contracts that are complex. An added difficulty is that projects that may appear to be simple and straightforward could have characteristics of complex projects and become increasingly difficult to deliver using conventional tools, techniques and approaches to contracting, even when some of these are considered to be best practice - for example, projects for which the schedule is compressed compared to previous norms for similar projects.

A formal contract is well understood in the context of a traditional contract but is expensive and often ineffective over the life cycle of a megaproject; indeed, it may even cause conflicts and prevent flexible and adaptive actions from being executed. In contrast, incomplete contracts that recognise that they contain uncertainty will require collaborative processes between contract parties to be realised which are beyond the familiar comfort zone of well-known contract practice.

\section{Discussion of issues}

The earlier sections of the paper have demonstrated that there appears to be a significant gap in understanding of the role and impacts on the performance and delivery of megaprojects of the full suite of documents forming the contract(s) between the parties. Owners who wish to transfer risk to their contractors and the supply chain often believe that this can be achieved by tightening up contract terms and increasing the amount of details in the contract documents despite little evidence to support this view. There is a lack of recognition that megaprojects require incomplete contracts due to their inherent complexity and uncertainty.

There appears therefore to be a widening gap between the shortfalls in the delivery of megaprojects and the perceptions of researchers exploring complexity or offering incremental solutions to project management performances that are successful in traditional projects but have not been so successful for megaprojects. Indeed, the failure to meet objectives may result in the development of techniques and tools that are not used due to contractual and legal constraints or that are not matched to the increased complexity of megaprojects. Despite performance shortfalls and increasing recognition of complexity, the requirement to keep within existing legal constraints means that the advice that owners obtain from their legal advisors will always tend to err on the side of caution, even when projects are moving away from the easily defined, linear and relatively straightforward delivery models of the past.

\section{Constraints imposed by contracts}

The preference of many owners is still for complete contracts, often with risks weighted heavily against the contractors and the supply chain. In theory, the risk can be priced so long as it is recognised and understood, but this is a naive approach by the standards of recent thinking on the management of megaprojects. There are several reasons for this.

- The extent of uncertainty makes tenders impossible either to plan or to price with any degree of certainty, meaning that contractors pricing for increasingly complex projects cannot be confident in the bid price or schedule, nor, of course, can the owners be.

- Unrealistically short durations for contractors to implement projects are unlikely to be achievable.

- Even if the tender is priced logically and completely taking risk allocation into account, competitive tendering means that bidders that have omitted or incorrectly assessed risk will have a price advantage. Any margins are likely to be further eroded as final negotiations are concluded against the backdrop of highly completive world markets.

From the perspective of contractors, owner delays and changes are unlikely to be fully compensated because owners are likely to invoke strict compliance with contracts' provisions for notifying and fully particularising claims. Contractors' failures to comply with contract provisions will be treated as legitimate reasons for rejecting claims for compensation, particularly for delay and the 
disruptive effects of changes. Since many effects of changes may be small and even incremental, the burden on contractors of identifying, notifying and quantifying impacts is substantial, and the result is unlikely to satisfy the strict legal standards of proof. Frequently, neither party wins: the project is late and over budget, but the contractor's margins have also been eroded or removed.

None of this is unknown. Experience suggests, however, that owners and their legal advisors place too much emphasis on trying to assure timely completion, price certainty and performance by transferring more risks to the supply chain. This can be counterproductive, particularly as far as timely completion is concerned. Delays, consequential increases in cost and lost revenues adversely impact individual projects, businesses, the health of the construction industry and possibly whole national economies (Flyvbjerg, 2014).

Strict allocation and 'management' of risks per the contract does little to encourage pragmatic, and usually more realistic, approaches to risk management. So-called risk events are rarely discrete events but more likely the consequence of multiple actions, inactions or external circumstances that are not confined to one or other of the parties to the contract. For example, Atkinson et al. (2006) stated that uncertainty in a variety of forms requiring management attention goes well beyond a set of possible events that might impair project performance. Similarly, if opportunities to improve the likelihood of the megaproject being successful are to be taken advantage of, more rather than less co-operation is likely to be required. Contract forms such as the NEC have been developed to address these concerns but have had little use outside the UK, public sector practice or countries influenced by UK practice, and as referenced earlier, there are concerns about their effectiveness.

Other specific areas constrained by contract forms include planning/ scheduling. In order to ensure that contractors' schedules comply with the generally recognised best practice, in the authors' experience, it has become common for contracts to specify in considerable detail the owner's requirements for scheduling down to explicit requirements for methods, levels of schedule detail and even the proprietary software to be used. This has the perceived benefit of, in theory at least, a suitable basis for the owner to assess properly if requests by contractors for extensions of time are realistic and demonstrable by accepted industry standards such as the Society of Construction Law's Delay and Disruption Protocol (SCL, 2017).

While this approach appears reasonable, the requirement to develop detailed schedules and programmes within the timescales available given the size and durations of megaprojects is unrealistic. Contractors cannot quickly develop sufficient reliable information to allow the development of fully detailed and resourced critical-path networks for submission to the owner for review and approval within a few weeks of contract start.

Theoretically, contractors could employ more resources to prepare programmes, but this has practical limitations such as obtaining and assimilating all the data and then assembling detailed schedules within a short period for megaprojects with multiple stakeholders, sometimes of different nationalities and capabilities; the key but almost wholly unrealistic assumption being that the baseline schedule will not change or will be changed only in specified ways and by specified mechanisms so that it can be used to measure entitlement to contractual extensions of time.

Contract management procedures and contract terms create bottlenecks due to resource constraints, particularly in owners' organisations. The timescales set out in contracts to deal with vast numbers of individual document and design reviews may be unachievable within the scheduled duration. This forces the contractor to proceed at risk. The difficulties of expediting approvals may be exacerbated by the division of responsibilities on the owners' side, particularly in the cases of consortia or joint ventures unless a clear governance structure is in place.

\section{Basis for further work}

There is clearly concern among all parties associated with megaprojects that the delivery and performance record is not good. This paper shows that improvements in project management and the modification and scaling up of traditional project contracts have so far made little positive impression on megaproject delivery and may encourage implementation of projects that have little chance of success. It appears that there needs to be a greater exchange of views between the various parties - and particularly the legal, procurement and project management disciplines - to seek to develop appropriate approaches. Factors militating against the achievement of the owners' objectives include the size and structure of many projects, which suggests that clearer recognition of the impact of these factors by both owners and contractors, together with their respective advisors, would help improve the quality of the contractual and management arrangements for projects.

A pragmatic approach would be to seek to match more closely the approaches between the, often conflicting, legal and contractual requirements and the most appropriate tools and techniques. Some relaxation of the specifications for, say, schedule and project controls tools could encourage the use of more flexible and more appropriate approaches. At present, however, there seems little hunger for what may be regarded as a more realistic approach to the management and contracting for megaprojects.

The main lesson from this paper that is suggested by the authors is that there is a case for new research to be focused on the relationship between contracts and the delivery of megaprojects. The incomplete nature of megaprojects must be taken into consideration. Certain risks are inherent specifically to megaprojects, and this must be recognised in forming any new approach. While not a panacea, it is clear that replacing the unsuccessful scaling up of traditional contract methods has the potential to improve megaproject delivery and avoid or reduce certain constraints. The view that transferring risk to the contractors will result in more certainty in achieving owners' objectives and may therefore lead to the implementation of projects that have no chance of success merits investigation. 
The authors would welcome written comments and contributions from practitioners and academics, including potential co-investigators, to help guide future research into the role of contracts in megaproject management and delivery.

\section{REFERENCES}

Atkinson R, Crawford L and Ward S (2006) Fundamental uncertainties in projects and the scope of project management. International Journal of Project Management 24(8): 687-698, https://doi.org:10.1016/ ijproman.2006.09.11.

Chen Y (2000) Promises, trust and contracts. Journal of Law, Economics and Organisation 16(1): 209-232.

Dimitriou H, Ward EJ and Wright PG (2012) Mega Projects Executive Summary: Lessons for Decision Makers: an Analysis of Selected International Large-scale Transport Infrastructure Projects. Omega Centre, Barlett School of Planning, University College London, London, UK.

Fellows R and Liu A (2010) Conflict on multi-national construction projects. Proceedings of the Institution of Civil Engineers Management, Procurement and Law 163(3): 101-110, https://doi.org/ 10.1680/mpal.2010.163.3.101.

Fidic (International Federation of Consulting Engineers) (2017) Conditions of Contract for EPC/Turnkey Projects, 2nd edn. Fidic, Geneva, Switzerland.

Flyvbjerg B (2014) What you should know about megaprojects and why: an overview. Project Management Journal 4(2): 6-19, https://doi.org/ 10.1002/pmj.21409.

Flyvbjerg B, Bruzelius N and Rottengarther W (2003a) Megaprojects and Risk: an Anatomy of Ambition. Cambridge University Press, Cambridge, UK.

Flyvbjerg B, Skamris holm M and Buhl SL (2003b) How common and how large are cost overruns in transport infrastructure projects? Transport Reviews 23(1): 71-88, https://doi.org/10.1080/01441640309904.

Flyvbjerg B, Glenting C and Ronnest AK (2004) Procedures for Dealing with Optimism Bias in Transport Planning. UK Department for Transport, London, UK.

Galloway PD and Reilly JJ (2013) Six challenges to controlling megaprojects. In Managing Gigaprojects: Advice from Those Who've Been There, Done That (Galloway PD, Nielsen KR and Dignum JL (eds)). American Society of Civil Engineers, Reston, VA, USA, pp. $151-186$

Gaski FF (1984) The theory of power and conflict in channels of distribution. Journal of Marketing 48(3): 9-29.

Glover J (2017) The FIDIC Rainbow Suite: What's New in 2017. Centre for Construction Law Open Forum, King's College London, London, UK.

Hosie J (2007) Turnkey Contracting under the FIDIC Silver Book: What Do Owners Want? Mayer Brown International, Chicago, IL, USA.

Kharbanda OP and Stallworthy EA (1983) How to Learn from Project Disasters. Gower, Aldershot, UK

Lee E, Park Y and Shin JG (2009) Large engineering project risk management using a Bayesian belief network. Expert Systems with Applications 36(3): 5880-5887, https://doi.org/10.1016/j.eswa.2008.07.057.

Lyons B and Mehta J (1997) Contracts, opportunism and trust: selfinterest and social orientation. Cambridge Journal of Economics 21(10): 239-257.

Merrow EW (2011) Industrial Megaprojects Concepts, Strategies and Practices for Success. Wiley, Hoboken, NJ, USA.

Miller R and Lessard D (2001) Understanding and managing risks in large engineering projects. International Journal of Project Management 19(8): 437-443, https://doi.org/10.1016/S0263-7863(01)00045-X.

Morgan T (2011) Briefing: Risk management critical to Crossrail's success. Proceedings of the Institution of Civil Engineers - Management Procurement and Law 164(2): 57-58, https://doi.org/10.1680/mpal. 2011.164.2.57.
Mousavi S, Tavakkoli-Moghaddam R, Hashemi H and Mojtahedi S (2011) A novel approach based on non-parametric resampling with interval analysis for large engineering project risks. Safety Science 49(10): 1340-1348.

Sainati T (2017) Design of Special Purpose Entities for Successful Megaprojects. PhD thesis, University of Leeds, Leeds, UK.

SCL (Society of Construction Law) (2017) Delay and Disruption Protocol. Society of Construction Law, Hinckley, UK.

Snowden D (2002) Complex acts of knowing - paradox and descriptive self-awareness. Journal of Knowledge Management 6(2): 100-111, https://doi.org/10.1108/13673270210424639.

Snowden DJ and Kurtz C (2003) The new dynamics of strategy: sensemaking in a complex and complicated world. IBM Systems Journal 42(3): 462-483.

Sykes A (1986) Success and failure of major projects. Civil Engineering, January/February, pp. 17-19.

Sykes A (1998) Megaprojects: grand schemes need oversight, ample funding. Forum for Applied Research and Public Policy 13(1): 6-47.

Turner JR and Cochrane RA (1993) Goals-and-methods matrix: coping with projects with ill-defined goals and/or methods of achieving them. International Journal of Project Management 11(2): 93-102.

Uff J (2017) Is the Construction Industry Waving or Drowning? Society of Construction Law, Hinckley, UK, paper D203.

UMIST PMG (Project Management Group, University of Manchester Institute of Science and Technology) (1989) A Guide to Cost Estimating for Overseas Development Projects. Overseas Development Authority, London, UK.

Valentin WS and Vorster FS (2012) Understanding construction project failure in southern Africa. Proceedings of the Institution of Civil Engineers - Management, Procurement and Law 165(1): 19-26, https://doi.org/10.1680/mpal.2012.165.1.19.

Watermeyer RB (2012) A framework for developing construction procurement strategy. Proceedings of the Institution of Civil Engineers - Management, Procurement and Law 165(4): 223-237, https://doi. org/10.1680/mpal.11.00014.

Williams TM (1999) The need for new paradigms for complex projects. International Journal of Project Management 17(5): 269-273, https://doi.org/10.1016/S0263-7863(98)00047-7.

Williams TM, Eden CL, Ackerman FR and Tait A (1995) The effects of design changes and delays on project costs. Journal of the Operational Research Society 46(7): 809-818.

Zheng J, Roehrich JK and Lewis MA (2008) The dynamics of contractual and relational governance: evidence from long term public-private procurement arrangements. Journal of Purchasing \& Supply Management 14(1): 43-54, https://doi.org/10.1016/j.pusup.2008.01.04.

\section{How can you contribute?}

To discuss this paper, please email up to 500 words to the editor at journals@ice.org.uk. Your contribution will be forwarded to the author(s) for a reply and, if considered appropriate by the editorial board, it will be published as discussion in a future issue of the journal.

Proceedings journals rely entirely on contributions from the civil engineering profession (and allied disciplines). Information about how to submit your paper online is available at www.icevirtuallibrary.com/page/authors, where you will also find detailed author guidelines. 